\title{
Sustainability Balanced Scorecard for a Brazilian agricultural and livestock company
}

\author{
Lindiana Araújo ${ }^{1}$, Helena Oliveira ${ }^{2, *}$ and Luís Gomes ${ }^{2}$ \\ ${ }^{1}$ Federal Institute of Goiás, Goiânia, 74690-900, Goiás, Brazil \\ ${ }^{2}$ Polytechnic of Porto, 4200-465, Porto, Portugal
}

\begin{abstract}
The agricultural sector in Brazil has a noticeable impact on its wealth and a significant effect on sustainability. This study presents the corporate sustainability management through the integration of social and environmental issues in the traditional Balanced Scorecard, that is, through a Sustainability Balanced Scorecard (SBSC). It establishes causal relationships between economic, social and environmental perspectives, and highlights its potential impacts. This study relays on the Brazilian company with the largest amount of agricultural land. This company acquires, develop, exploit and commercialize rural properties that are suitable for agriculture. The main purpose of this paper is to study the company and to propose an SBSC. We present a qualitative case study based on interviews and on documental analysis. We conclude that, through this framework, sustainability can be aligned with the strategic management of the company. The implementation of an SBSC provides organizational benefits and must take into consideration the peculiarities of each organization.
\end{abstract}

\section{Introduction}

The integration of sustainability in strategic business management is possible through a Balanced Scorecard (BSC). The sustainability features represent externalities that are not fully integrated with the market exchange processes but with social practices. However, inevitably the performance of the companies ends up being related to such features, which may become strategically relevant [1]. The awareness of the strategic potential of environmental and social issues has been increased. The importance to manage, monitor, and measure the performance of environmental and social issues highlights the concern with corporate sustainability management systems [2]. Sustainability management systems are being used such as the BSC through its extension to the Sustainability Balanced Scorecard (SBSC)[3]. These management tool foster organizations to contribute to sustainability issues improving fully their environmental, social and economic practices [1].

In this paper, we study how the strategic alignment of sustainability can be done with the corporate business, considering the particularities of the organizational. We also highlight the importance of the implementation of an SBSC.

\footnotetext{
* Corresponding author: helena@iscap.ipp.pt
} 
Concretely, we began with the four traditional perspectives of the BSC (namely financial perspective, customers, internal processes, and learning and growth) and integrate a sustainability perspective drawing up an SBSC for an agriculture and livestock company in Brazil. According to the Brazilian Ministry of the Environment (2018), the overcome of incongruity between production and environmental protection is a huge challenge imposed on the rural sector. The dilemma presented is on the one hand to reverse the degradation of ecosystems caused by agriculture and livestock, and on the other, to promote and develop rural production in a sustainable way. For the agriculture and livestock sector can produce, many areas of forests are cleared for planting crops, pastures, and livestock. This causes huge social and particularly environmental impacts. In this sense, with this study, we intend to contribute to this field. Several issues need to be raised, addressed and directed to entrepreneurs so they can get the necessary knowledge and tools to enable conscious and responsible management of their business. This way benefits will be arising for their organization, society, economy and for the global environment.

The paper is structured in six sections. The following section presents the literature review. Then we present the method used in the study, the case study containing the design of the SBSC and the strategic map. Section five discusses the results and we end up with the conclusions in the last section.

\section{Sustainability Balanced Scorecard}

Sustainability management relates environmental and socioeconomic actions with sustainability, putting them into action and evaluate their results [4]. Since 1995 academics began studying corporate sustainability recognizing that unsustainable business practices needed to be changed. However, many corporations were criticized for misrepresenting sustainability management as the benefits were focused only on the organizational level. Such benefits need to be extended systemically so that sustainability challenges contribute to sustainable development and enable a radical change rather than a non-incremental [5]. According to Lee and Saen [6], it is necessary to adopt corporate sustainability management practices although there is a lack of tools to support operationally such practices. Schaltegger and Burritt [7] argue that anyone who seeks for sustainable development as a corporate goal, sooner or later, will face issues related to metrics to operationalize sustainability and related to their communication.

\subsection{Sustainability in the Balanced Scorecard}

The BSC is a management tool that presents financial and operational performance measures, providing managers an agile and broad view of business [8]. The measurement of financial factors, through income statements, balance sheets, and other traditional accounting reports, is a very limited procedure. The achievement of objectives is based only in past actions, restricting the need of present operational actions to achieve future performance. The BSC enable the achievement of leading indicators as well as lagging indicators providing efficiency and effectiveness of past actions. It combines financial and non-financial measures in the internal corporate process allowing managers to evaluate the effectiveness of strategic plans and actions [9].

The BSC strategic map is a systemic representation of cause and effect relationships between the several objectives. It provides a logical and comprehensive approach to understanding business strategy. It expresses the organization aimed results and paths to achieve them. Thus, the BSC became a strategic communication tool for all organization, including employees and organizational units [10]. 
The BSC can be an appropriate tool to manage corporate sustainability [11]. According to Kaplan and Norton [12], different market situations, product strategies and competitive environments require different scorecards. The business units create custom scorecards to fit their mission, strategy, technology, and culture. Schaltegger and Burritt [7] argue that conventional corporate accounting systems need to be revised to incorporate environmental and social issues and their financial effects. The SBSC has its origin in the traditional BSC, presenting a different content and architecture by integrating the three sustainability dimensions [13]. For Kalender and Vayvay [14] sustainability is the fifth pillar of the BSC. Thus, for the SBSC to be implemented, it is necessary and crucial the definition and implementation of environmental, social and economic strategies for a corporate sustainability [11].

This approach allows the companies to contribute to sustainability issues, improving their performance and their social, environmental and economic effects, in an integrative way [1]. This model conduct to develop organizational sustainability and performance through the integration of severing criteria for decision making [15].

The model can also be useful for defining performance indicators in sustainability assessment models and can be integrated into multi-criteria decision methods to improve organizational sustainability and performance.

The architecture of SBSC can be done in two ways. It is possible to consider the sustainability objective into the four traditional perspectives of BSC or create a new performance perspective to consider those objectives [16].

\subsection{Integration and Architectures of SBSC}

Sustainability issues can be embedded in the BSC through the integration of environmental and social objectives into the four traditional perspectives or thought the creating a new specific perspective for sustainability management. The first option considers strategically relevant traits of sustainability in the BSC's perspectives. These traits linked and adapted to the pre-established cause and effect structure, converge to the financial perspective and allows a successful business strategy. However, it is important that these aspects have economic characteristics [1]. According to Moller and Schaltegger [16], this approach enables the integration of sustainability issues significant to the market: financial market, customers, suppliers or the labour market. In this sense, the study by Hansen and Shaltegger [2] identifies a strictly hierarchical architecture in which all strategic objectives lead to the achievement of financial results. In this instrumental profile, managers seek profit maximization and competitiveness.

Since environmental and social issues are non-economic, they represent externalities. Firms often act beyond the economic-financial field, interacting with other aspects, such as social and legal [1]. Thus, the integration of sustainability aspects absents in the market system, but strategically relevant in the BSC, will be better integrated following the second option, in which a fifth and new perspective will be created [1]. Hansen and Schaltegger [2] also present a non-hierarchical architecture in which all strategic objectives and perspectives are networked, both having their own rights, addressing diverse stakeholder interests.

According to its formulation, an SBSC is based in three phases: selecting the strategic business unit, identifying the environmental and social exposition of the business unit and determining the strategic relevance of environmental and social traits [1].

\section{Method}

\subsection{Characterization of the Study}


We present a qualitative case study [17] based on the design of an SBSC for a large Brazilian agricultural and livestock company. This activity sector contributes the most significant to the Brazilian Gross Domestic Product. We choose this company as it belongs to the primary sector, with few studies in management and control field. Also, this company has the peculiarity to be one of the few companies in the agricultural sector listed on the BM\&F Bovespa.

\subsection{Data Collection and Analysis}

This study was conducted in 2018. The data collection for the constructions of the SBSC were based on document analysis and interviews. After the collection, the date was analysed and submitted to the company for validation and accuracy.

We started with documentary analysis based on the company's website information and on other documentation provided by the company, namely: sustainability reports, work safety reports, environmental impacts reports, among others. The company disseminating highquality sustainability information. This analyses enabled the identification of strategically relevant aspects regarding environmental, social and economic. These documents contributed to the assessment of vision, strategy, possible strategic goals, and values. It also enables the identification of features and the main concern of the organizational essential the construction of the SBSC. Thus, we started with the construction of Kaplan and Norton's strategy translation structure, identifying strategic objectives for each BSC traditional perspective. Beside these perspectives, we consider another one for sustainability contemplating social and environmental issues. We end up with five perspectives: the financial perspective, customers, internal processes, learning and growth, and sustainability. The company's overall strategy and operational initiatives were identified and documented.

Since the organization does not know the SBSC tool an initial research assignment was sent in order to allow them to follow the research and comprise it.

To consolidate the study, we proceed with the interviews. The interviewers were relevant managers and actors who are closely involved with research. A script was sent in advance to the interviews. The questions were pre-determined although interviews have some freedom. We conducted two interviews with an average duration of 50 minutes, one to the Environmental and Safety at Work Coordinator and the other to the Environmental Analyst of the Company. The interviews aimed to complement and validate the SBSC and highlight other specific sustainability issues of the company.

Finally, the collect information was sent to the company for validation and accuracy. Based on the information collected a strategic map was developed, reflecting the cause and effect relationships between the five perspectives of the SBSC. The company under study has a fictitious name: AGRITERRAS.

\section{Results}

Initially, we sought to understand what tools the company uses to communicate its objectives and goals to its employees and to measure and manage their performance. In this way, we identify that the company has a sustainability report, climate research, as well as performance evaluation, and communicates its strategic objectives through an internal information system.

We began to elaborate the SBSC based on its strategy, vision, and mission, according to Kaplan and Norton [10]. For AGRITERRAS the main strategy is the valorisation of their rural properties. 
One of the success factors for the formulation and implementation of a corporate sustainability strategy is the organizational culture [18]. This involves the perception of the company's employees about it. In this sense, we seek to perceive whether the organizational culture of AGRITERRAS is favourable for the formulation of an SBSC, and this is a main issue for the corporation. According to the Environmental and Occupational Safety Coordinator the company shares sustainability information with the public and with their collaborators. They organize lectures to present the farm's reality to the communities. Its employees show interest and are participative. In Great Place to Work's climate research, one of the most relevant issues was the proud employee have on their organization's business. So the employees feel good in the company and approve their sustainability practices.

After understanding the corporate strategy, the mission, the vision and the organizational culture of AGRITERRAS, we identify the components of BSC perspectives. For each of the five perspectives (financial, customers, internal processes, learning and growth, and sustainability) we identify the objectives, the critical performance factors and the initiatives, according to Kaplan and Norton [8]. We highlight the sustainability perspective.

For the financial perspective we identified five objectives: the valuation of rural properties; maximizing return on investments; capital gains return; efficient allocation of capital between investment and acquisition; and minimization of risks of commodity prices.

The performance measures determined for each financial objectives are: the variability of the rural properties value through an independent consultant's evaluator; net profit or net income for the objective; the profit or loss obtained from the sale of rural properties; the Internal Rate of Return; and the percentage of losses or gains in commodity prices through derivative transactions.

Initiatives of AGRITERRAS identified for each obejctive / mesaure are: to identify, acquire, develop and exploit rural properties with high potential for recovery; actively manage the portfolio of rural properties; selective sale of developed rural properties; acquisition of underutilized or non-productive rural properties at attractive prices and acquisition of raw materials at the lowest cost; and develop of the rural properties portfolio diversifying by region and tilth production and using derivative instruments.

The measures of financial performance reveal whether the implementation and execution of the strategy are contributing to the improvement of the bottom line. Typical financial objectives are related to profitability, growth and shareholder value [8].

We identify as objectives of AGRITERRAS for the customer's perspective: conclude lease agreements; property sell when ideal market value achieved; and be transparent with investors/costumers.

The performance measures determined for each objective from the Customer's perspective were: net sales revenue from agricultural products in leasing; or farm sales; and the number of communications, reports, and conferences held.

Two initiatives are proposed: improving rural properties through investments, infrastructure, and technology; and disclosure objectively the results through the elaboration of webcasts and conferences.

The $\mathrm{BSC}$ requires the translation of the mission into customer services, measuring the customer's most relevant interests [8].

In the perspective of internal processes, we identify the following objectives: implement higher value-added crops; implement excellence technology and agricultural techniques; increase operational productivity; mitigate climate and crop risks; and controlling diseases and pests in crops and livestock.

The performance measures determined for each objective from the internal processes perspective were: the profitability of the implemented crops; percentage of waste related planting, harvesting and labour processes; the number of PPR's assigned to employees (a 
variable remuneration used to align the strategies to the productivity of its employees); the number of crop losses; and the amount of crop and livestock losses due to diseases and pests.

The introduction of the agricultural in lands, development of its productivity and improve its infrastructure; transformation of rural properties into pastures or implementation of agricultural activities, such as grains, sugar cane, pasture, and forest; transformation of pastures into more productive agricultural properties such as sugar cane plantation; improve rural production thought profitable agricultural activities based on culture and technology issues; the use of genetically modified and high-yielding seeds; the hiring of quality service providers, and the geographical and productive diversification of rural properties are initiatives that improve AGRITERRAS's internal processes.

According to Kaplan and Norton [8], the definition of internal processes is very important in order to enable the achievement of customer satisfaction. Customer satisfaction and company actions derive from internal processes. Thus, managers should pay full attention to the critical internal processes since it enables the achievement of customer expectations.

Regarding the learning and growth perspective several objectives were defined: region and properties infrastructures optimization; rural properties income and productivity optimization; captivate and develop people; satisfaction and loyalty of employee.

The measures identified for each objective in this perspective were: the number of infrastructures implemented; percentage of growth of products harvested and in commercialization condition; the number of sponsored scholarships and the number of qualified employees, and employee turnover rate.

Initiatives from this perspective can contribute to the learning and development of employees, as well as the growth of the corporation. We recognise the offer of training for business leaders, developing scholarships for undergraduate courses, and incentives for employees in order to obtain the best return on investments.

According to Kaplan and Norton [8], the goals for success are constantly changing. Intense global competition requires continuous improvements in company products and processes, and the ability to introduce brand new products with expanded capabilities.

The objectives identified for the sustainability perspective were: to make the entire agricultural chain sustainable; mitigate and minimize negative environmental impacts; promote the continuous improvement of the environment; safety and quality of life, and social development.

The performance measures identified for each objective are: the number of environmental problems caused by the company's activities; the amount of non-recycled waste; the number of degraded areas recovered; the absence of employee due to health reasons; the number of lodging complaints; and social vulnerability rates of the regions.

For Bieker [13] similar to the traditional BSC concept, the definition of a sustainability strategy at the corporate level seems crucial. For this, it is necessary to define the perspective objectives, the measures, and the performance indicators. For the company sustainability is more than complying with environmental laws, being part of the business in the moment of selling and also buying lands. When buys lands the company assess if the environmental and sustainability are respected. Also, they gauge if it is possible to add value both for the company and for the community, in order to bring economic and social development to the respective regions. The company and all employees, whether to buy or sell land, have always in consideration the sustainability issues, which is one of the main business pillars.

Table 1 contemplates the operational strategy translation in terms of the sustainability perspective. 
Table 1. Organization of the strategic objectives, from the AGRITERRAS' sustainability perspective.

\begin{tabular}{|c|c|c|c|}
\hline OBJECTIVES & MEASURES & INITIATIVES & TARGETS \\
\hline $\begin{array}{l}\text { Make the entire } \\
\text { agricultural chain } \\
\text { sustainable. }\end{array}$ & $\begin{array}{c}\text { Number of } \\
\text { environmental } \\
\text { problems caused } \\
\text { by the company's } \\
\text { activities. }\end{array}$ & $\begin{array}{l}\text { Control and evaluate } \\
\text { activities and services, work } \\
\text { with governmental and non- } \\
\text { governmental bodies and } \\
\text { compliance with } \\
\text { environmental legislation. }\end{array}$ & $\begin{array}{c}\text { The decrease in } \mathrm{X} \% \\
\text { of the negative } \\
\text { environmental } \\
\text { impacts. }\end{array}$ \\
\hline $\begin{array}{c}\text { Mitigate and } \\
\text { minimize negative } \\
\text { environmental } \\
\text { impacts. }\end{array}$ & $\begin{array}{c}\text { The amount of } \\
\text { non-recycled } \\
\text { waste. }\end{array}$ & $\begin{array}{l}\text { Waste recycling, awareness, } \\
\text { and involvement of } \\
\text { employees and the local } \\
\text { community. }\end{array}$ & $\begin{array}{l}\text { Recycling X\% of } \\
\text { our waste. }\end{array}$ \\
\hline $\begin{array}{l}\text { Promote the } \\
\text { continuous } \\
\text { improvement of the } \\
\text { environment. }\end{array}$ & $\begin{array}{l}\text { The number of } \\
\text { degraded areas } \\
\text { recovered. }\end{array}$ & $\begin{array}{c}\text { Investment in soil } \\
\text { conservation technologies } \\
\text { and practices such as no- } \\
\text { tillage, crop rotation, } \\
\text { integration system for } \\
\text { livestock farming and } \\
\text { institution of ecological } \\
\text { corridors. }\end{array}$ & $\begin{array}{l}\text { Investment } \mathrm{X} € \text { in } \\
\text { conservation } \\
\text { technologies and } \\
\text { practices. }\end{array}$ \\
\hline $\begin{array}{c}\text { Safety and quality of } \\
\text { life. }\end{array}$ & $\begin{array}{l}\text { The absence of } \\
\text { employee due to } \\
\text { health reasons } \\
\text { and the number } \\
\text { of lodging } \\
\text { complaints. }\end{array}$ & $\begin{array}{l}\text { Follow-up with labour and } \\
\text { social security obligations. } \\
\text { Appropriate working } \\
\text { conditions. Accommodation } \\
\text { and housing. Individual } \\
\text { safety equipment's. Health } \\
\text { care. Dental care. Risk } \\
\text { management. }\end{array}$ & $\begin{array}{l}\text { Improvements in } \\
\mathrm{X} \% \text { the } \\
\text { accommodations. } \\
\text { Investment in } \\
\text { medical and dental } \\
\text { care. }\end{array}$ \\
\hline Social development. & $\begin{array}{c}\text { Social } \\
\text { vulnerability rates } \\
\text { of the regions. }\end{array}$ & $\begin{array}{l}\text { Dynamization of regional } \\
\text { economies, creating } \\
\text { employment and } \\
\text { accommodation for the rural } \\
\text { population. Improvements in } \\
\text { the surroundings of } \\
\text { properties, such as the } \\
\text { construction of schools, the } \\
\text { implementation of the } \\
\text { electric network, and the } \\
\text { creation of local jobs. } \\
\text { Promote social actions with } \\
\text { children and adolescents } \\
\text { from schools in the action } \\
\text { company area: the states of } \\
\text { Goiás, Bahia, and Maranhão. }\end{array}$ & $\begin{array}{l}\text { Promote X social } \\
\text { projects in } \\
\text { communities. }\end{array}$ \\
\hline
\end{tabular}

Following the design of an SBSC, we will identify and align strategically relevant aspects, translating the strategy into linked objectives, and indicators [1].

The formulation of the vision, mission, strategy, strategic objectives, and features, and also the analysis of the relevance strategic of sustainability for AGRITERRAS were systematized in its strategic map, in Figure 1.

According to Krstić, Sekulić, and Ivanović [19], the formulation of an SBSC can be presented graphically through a strategic map. We can see from the below strategic map that the integration of the sustainability issues of AGRITERRAS in the BSC was made through 
a new (the fifth) perspective. This perspective manager the sustainability objectives. Such objectives do not present economic characteristics, however, they are strategically very relevant for the business [1]. Butler, Henderson, and Raiborn [19] also emphasise the integration of sustainability through a fifth perspective. The case study reveals that the company considers sustainability as an organizational value. Consequently, in addition to the strategic objectives identified for the four traditional perspectives of the BSC, it considered a fifth strategic objective into the perspective of sustainability, addressing environmental and social issues.

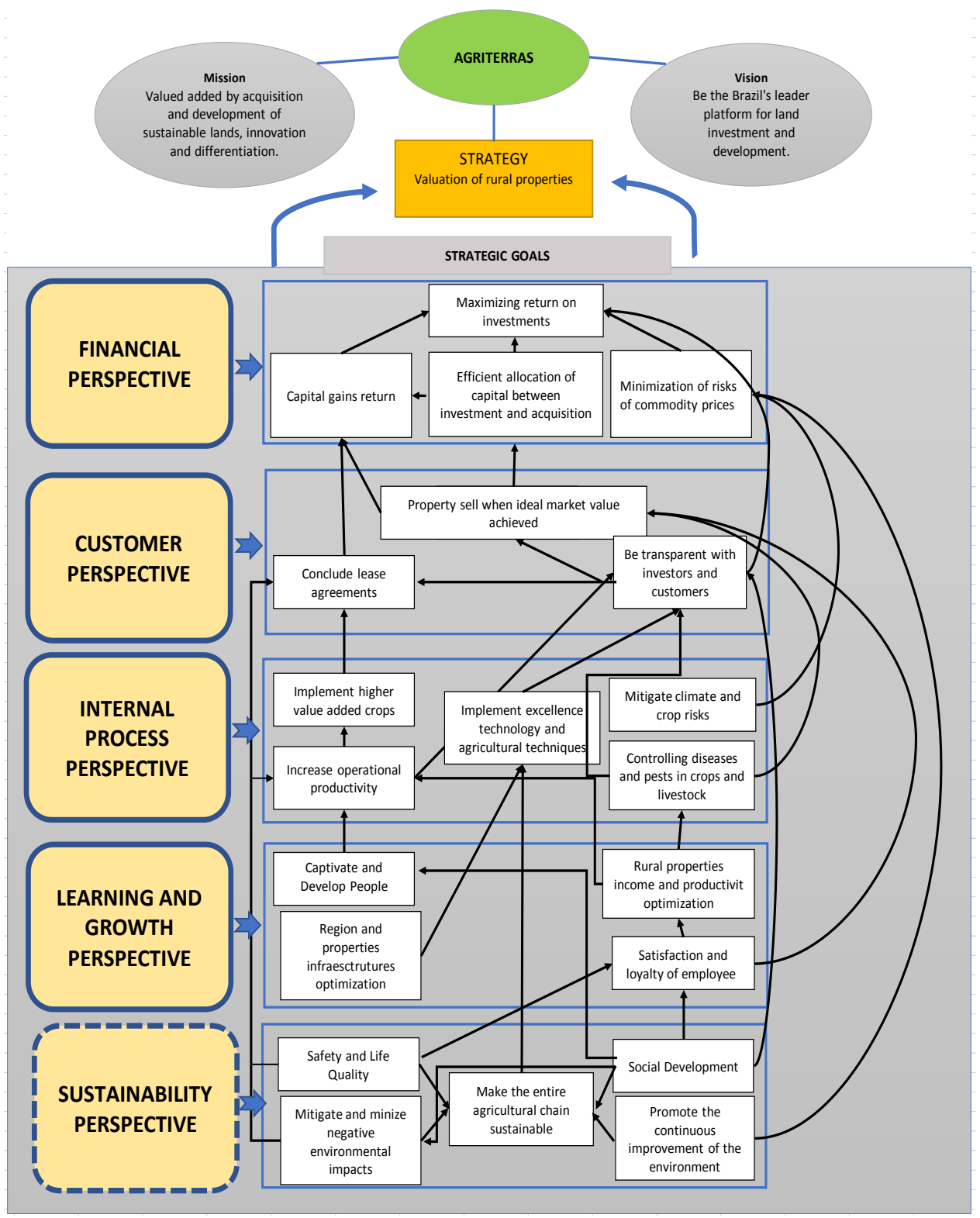

Fig. 1. Strategic Map of AGRITERRAS. 
Analysing the AGRITERRAS's strategic map, clearly and quickly we understand the cause and effect relationship between each perspective. Also, it is possible to recognise the strategic influences of sustainability among the other perspectives, corroborating the study by Bieker [13].

Corroborating the study of Krstić, Sekulić, and Ivanović [19] we observe that the lower levels of key success factors can boost the higher-level goals and perspectives. In this way, we can highlight these relationships in the strategic map of AGRITERRAS, for example: safety and quality of life (which is an objective of the sustainability perspective) leads to satisfaction and loyalty of employee (impacting the learning and growth perspective) and to increase operational productivity, which is part of the internal process perspective.

\section{Discussion}

The strategic alignment of sustainability to the organizational business was possible by the identification of the strategic relevance of sustainability aspects that impact the organization. We analysed whether sustainability issues have economic characteristics and their impact on the market. The traditional BSC model presents a great potential for this linkage.

The case study reveals that the SBSC could provide to AGRITERRAS an information aggregation in a single tool. This aggregation provides the communication of the strategic objectives and goals to the employees and to the whole organization, constituting the measure of performance in several business dimensions. Currently, the corporation uses three separate tools for a common propose: the sustainability report, the organizational climate survey, and the information system. The SBSC could integrate them.

The design of the SBSC is specific according to the particular features of the company. It is essential to take into consideration the "personality" of the corporation. Several features have to be taken into consideration such as the business strategy, the sustainability strategic, organizational values, culture and, structure, leadership involvement, the strategic planning process, among others. The company studied belong to the primary sector, therefore its activities are mainly related to environmental issues. This is a crucial issue for business operationalization, becoming strategically relevant. Already companies belonging to other sectors such as the industry and commerce sectors, have a quite different BSC. Hence, following Kaplan and Norton [12] recommendation this BSC was developed specifically according to the "personality" of AGRITERRAS.

In addition, the case study reveals that the company has a lot of useful and strategic information scattered and dispersed through the company. This information has several formats such as public documents, reports, institutional presentations, conferences, and websites. Corroborating Kaplan and Norton [8] arguments, the organization of such information according to the BSC structure allow a direct and clearer understanding of the crucial factors, and helpful support for decision making by managers, employees and also potential investors. Hence, empowers competitive advantages and elucidates several management and investments for possible actions that otherwise were hidden. It can also highlight issues that never have been discussed before.

The results also provide evidence that there are several reasons for the design and implementation of an SBSC. It allows sustainability to be integrated and managed strategically. Thus, it allows the integration of social and environmental initiatives into the corporate financial results and the understanding of business activities impacts on the internal and external environment [6]. This study advocates the conciliation between sustainable development and economic and financial development, and most of all strategically.

\section{Conclusions}


This study relies on the SBSC, proposing one for a Brazilian company with the largest amount of agricultural land and with the aim of acquiring, develop and exploit appropriate rural properties to agricultural.

The sustainability can be aligned with the company strategic management through an SBSC. This alignment can be an enabler of transformation, an intangible asset to provide competitive advantages, and measurement of benefits in the long term.

The implementation of an SBSC leads to the operational translation of the strategy; to the organization of strategic objectives; to clarify the strategic and operational business to managers and investors; to enable the communication and understanding of the strategy, objectives and goals all over the company; to understand the strategic relevance of sustainability; the causes and effects of sustainability in the several organizational domains; and the measurement of the results follow-on the management of environmental, social and economic practices.

The particularities of the organization influence the creation of an SBSC. The organization vision, mission, values, culture, strategy and business model are individual factors that boost the design of the SBSC.

There are several reasons to implement an SBSC. This tool can be a starting point to mature sustainability and sustainable development issues and to impact meaningful not only in companies but also in society.

This study encourages further discussions related to the design, operationally and effectiveness of an SBSC. Also, it raises issues related to the strategic management, performance and sustainability in one of the most important economic sectors in Brazil - the agricultural and livestock sector.

Despite the peculiarity of each company, the presented SBSC model can attend to be a started point for other companies, properly adjusted to their features.

As far as we know there are no studies about SBSC in the primary sector. Having this sector a significant weight in the national Gross Domestic Product in Brazil, we consider this study relevant.

As a limitation of the study we highlight the method - case study - so the conclusions cannot be generalized, since they are specific to the studied case.

For future research, we suggest additional studies on the subject, especially in the Brazil agricultural sector. We also suggest to studied different forms of integration the sustainability in the BSC or to study the impacts of SBSC implementation in the long term in a company. To improve the tool, the causes of the failure to implement the SBSC can also be studied.

\section{References}

1. F. Figge, T. Hahn, S. Schaltegger, \& M. Wagner, Bus. Strateg. Environ., 11, 269284 (2002)

2. E. Hansen, \& S. Schaltegger, J. Bus. Ethics 133, 193-221 (2016).

3. Z. Tuğçe, \& Ö. Vayvay. Procedia - Soc. Behav. Sci. 235, 76-83 (2016).

4. M. Starik. \& P. Kanashiro Organ. Environ. 26, 7-30 (2013).

5. T. Hahn \& F.Figge. J. Bus. Ethics 150, 919-935 (2016).

6. K. Lee \& R. Saen. Int. J. Prod. Econ. 140, 219-226 (2012).

7. S. Schaltegger \& R. Burritt J. World Bus. 45, 375-384 (2010).

8. R. Kaplan \& D. Norton, Harv. Bus. Rev. 70, 71-79 (1992).

9. J. Butler, S. Henderson \& C. Manag. Account. Q. Winter 12, 1-10 (2011).

10. R. Kaplan, \& D. Norton, Part I. Account. Horizons 15, 81-104 (2001).

11. T. Bieker \& B. Waxenberger, Internacional Conference of the Greening of Industry Network, Goteborg, Suécia (2002).

12. R. Kaplan \& D. Harv. Bus. Rev. September, 134-147 (1993). 
13. T. Bieker, Corporate sustainability: theoretical perspectives and practical approaches (ed. Oehme, \& U. S. (Ed. .) 121-146 (München: Profil, 2005).

14. Z. Kalender \& O. Vayvay, Procedia - Soc. Behav. Sci. 76-83 (2016).

15. A. Junior, M. Oliveira \& A. Helleno, J. Clean. Prod. 190, 84-93 (2018).

16. A.Moller \& S. Schaltegger, J. Ind. Ecol. 9, 73-83 (2005).

17. R. Yin, Thousand Oaks: Sage Publications, 1994.

18. S. Engert \& R. Baumgartner, J. Clean. Prod. 822-834 (2016).

19. B. Krstić, V. Sekulić, \& V. Ivanović, Econ. Themes 52, 65-80 (2014). 